Check for updates

Cite this: RSC Adv., 2017, 7, 28535

Received 1st May 2017

Accepted 24th May 2017

DOI: $10.1039 / c 7 r a 04882 c$

rsc.li/rsc-advances

\section{Carbon nanotubes synthesis using carbonization of pretreated rice straw through chemical vapor deposition of camphor}

\begin{abstract}
Nady A. Fathy (iD *
There is a pressing demand to prepare low-cost carbon nanotubes (CNTs) from renewable biomass resources as cheap carbon precursors and catalyst supports during chemical vapor deposition (CVD). Camphor and rice straw are quite an eco-friendly, renewable and low-cost carbon sources to prepare CNTs. Here, successful attempts for preparing CNTs through carbonization of hydrothermally treated rice straw using either mono-catalyst of ferrocene (RS-H/Fe) or mixed catalysts of ferrocene and nickel nitrate (RS-H/Fe-Ni) in presence of gaseous carbon source emitted from heating camphor under flowing $\mathrm{N}_{2}$ gas were achieved. Scanning electron microscope (SEM) combined with energy-dispersive spectroscopy (EDS), transmission electron microscope (TEM), Raman spectroscopy and thermal gravimetric analysis (TGA) techniques were used to determine the morphology, surface, electronic structures and thermal stability of the produced CNTs. Different structures of CNTs were grown with outer diameters ranging from $22 \mathrm{~nm}$ to $66 \mathrm{~nm}$. Few amounts with small outer diameters of coiled CNTs-Fe bundles were produced over carbonized rice straw with ferrocene (RS-H/Fe) through a bottom growth mechanism. Whereas considerable amounts of straight and large outer diameter of CNTs-bundles (CNTs-Fe-Ni) were formed over RS-H/Fe-Ni substrate via a bottom growth mechanism also. Raman spectra showed two main bands of CNTs; G-band at $1580 \mathrm{~cm}^{-1}$ and D-band at $1356 \mathrm{~cm}^{-1}$ or $1335 \mathrm{~cm}^{-1}$ which obtained on $\mathrm{RS}-\mathrm{H} / \mathrm{Fe}$ and $\mathrm{RS}-\mathrm{H} / \mathrm{Fe}-\mathrm{Ni}$ samples, respectively. Conclusively, the presence of $\mathrm{Ni}$ with ferrocene can enhance the yield, thickness and graphitization extent of the asprepared CNTs. Therefore, conversion of available-cheap biomasses into high added-value materials such as CNTs becomes a realistic, feasible and thus reduces the cost production of CNTs.
\end{abstract}

\section{Introduction}

Carbon nanotubes (CNTs) have been one of the most popular one-dimensional carbon nanomaterials since their discovery by Iijima in $1991 .^{1}$ The unique structure of CNTs endows them with superior electronic, optoelectronic, mechanical, and chemical properties, and they can be considered as semiconducting or metallic materials. ${ }^{2-10}$ Currently, they are synthesized by three common processes including the arc discharge, ${ }^{11}$ the laser ablation ${ }^{12}$ and the chemical vapor deposition (CVD) from catalytic decomposition of hydrocarbons on transition metals at high temperatures. ${ }^{13-20}$ Practically, CVD process is recognized as the most promising technique for industrial scale-up. Synthesis of CNTs is mainly controlled by type of carbonaceous feedstocks, catalysts, substrates and the necessary power consumption through CVD process. ${ }^{3}$ Different petroleum hydrocarbons in gas-form such as methane, ethylene and acetylene or in liquid-form like alcohols, benzene, xylene

Physical Chemistry Department, National Research Centre, 33 El Bohouth Street (former Tahrir st.), Dokki, P.O. 12622, Giza, Egypt. E-mail: fathyna.77@hotmail. com; na.fathy@nrc.sci.eg; Fax: +20 2 33370597; Tel: +20 233371433 and cyclohexane were used extensively as CNTs precursors. ${ }^{3-9}$ Also, several inorganic substrates like graphite, quartz, silicon, silicon carbide, silica, alumina, zeolite, $\mathrm{CaCO}_{3}, \mathrm{MgO}$, etc., which are relatively expensive materials which supported some catalysts such as Fe, Ni, Co, Mo, etc., in mono-, bi- or tertiary forms were reported in the CVD process..$^{6-8,10-22}$

Based on the growing environmental concern and increasing CNT demand, many investigations have carried out to develop a sustainable technology and to increase the mass production of CNTs. For example, renewable and eco-friendly botanical materials such as camphor, ${ }^{14,15}$ oiled-petroleum wastes such as turpentine oil, ${ }^{16}$ deoiled asphalt ${ }^{17}$ and eucalyptus oil ${ }^{18}$ as well as some vegetable oils such as coconut, ${ }^{19}$ neem, ${ }^{20}$ palm oil ${ }^{21}$ or waste cooking palm oil ${ }^{22}$ as starting materials in CNTs production were studied.

Recently, few works have focused on the optimization and simplification of synthesis of carbon nanotubes through utilization of agro-residues. Goodell et al. ${ }^{23}$ reported that CNTs with outer diameters from 10 to $20 \mathrm{~nm}$ can be prepared from wood fiber using continuous oxidation at $240{ }^{\circ} \mathrm{C}$ within several cyclic oxidations at $400{ }^{\circ} \mathrm{C}$ in presence of controlled amount of oxygen, whereas no CNTs produced from pure cellulose and 
lignin. They proposed that the obtained molecular structure of CNTs is closely related to the hexagonal arrangement of carbon atoms in the graphite sheets and thus the spatial and molecular arrangement of cell wall played an important role in the formation of CNTs. Very recently, Zhu et al. ${ }^{24}$ synthesized CNTs from bamboo charcoal using CVD in the presence of ethanol vapor and pyrolysis temperature between 1200 and $1400{ }^{\circ} \mathrm{C}$. They observed that the tips of MWCNTs produced consisted mainly of calcium silicate acting as a catalyst to accelerate the nucleation of MWCNTs. Lately; graphenated-CNTs (g-CNTs) materials were synthesized from waste rice husk $(\mathrm{RH})$ by onestep microwave plasma irradiation (MPI) process. ${ }^{25}$ Through this technique, which is very expensive and complicated, the obtained g-CNTs were composed of graphene standing on the sidewalls of CNTs, in which the graphene sheets possessed a large amount of sharp edges, which mainly consisted of 2-6 layers, and the CNTs had several tens of micrometers in length and 50-200 in diameter. ${ }^{25}$

Rice straw is one of the abundant lignocellulosic waste materials in the world where its massive production was estimated to be between 650 and 975 million tons per year. ${ }^{26,27}$ There is no practical use for these by-products, up till now, except as a fuel source. Up-to-date, the use of hydrothermally treated rice straw as a potential biomass for preparation of CNTs through a green nanotechnology method has not been demonstrated yet. In this study, the production of carbon nanotubes (CNTs) was carried out by two sequence steps; (i) hydrothermal treatment and (ii) chemical vapor deposition method.

The current work explores some attempts for production of CNTs-bundles via a chemical vapor deposition of camphor through carbonization of hydrothermally treated rice straw, supported either with ferrocene or ferrocene-nickel catalysts. The growth morphology of CNTs during this advanced process was evaluated using means of SEM and TEM while electronic properties and thermal stability of the produced CNTs were assessed by Raman spectroscopy and TGA techniques, respectively.

\section{Experimental}

\subsection{Pretreatment of rice straw by alkali-acid reagents}

Prior hydrothermal treatment, the rice straw was collected from Delta region in Egypt, washed thoroughly with hot water for several times then dried overnight at $80^{\circ} \mathrm{C}$. Rice straw was milled, sieved in range of $0.4-0.8 \mathrm{~mm}$ (denoted as RS). The RS was treated with $\mathrm{NaOH}$ by mass ratio $1: 1$ in $1 \mathrm{~L}$ distilled water to remove the silica, lignin, hemicellulose and other pectin substances. The mixture was stirred and heated at $100{ }^{\circ} \mathrm{C}$ for $120 \mathrm{~min}$ then left overnight. After that, the alkali treated rice straw was filtered, washed with hot water and dried overnight at $80{ }^{\circ} \mathrm{C}$. Then, acid treatment of pretreated rice straw in alkali was employed by the refluxing as follows; $2 \mathrm{~g}$ of pretreated rice straw was inserted into $250 \mathrm{~mL}$ a round bottle containing $100 \mathrm{~mL}$ of $10 \mathrm{v} / \mathrm{v} \% \mathrm{H}_{2} \mathrm{SO}_{4}$ acid and heated at $100{ }^{\circ} \mathrm{C}$ for $120 \mathrm{~min}$ under continuous stirring. After that, the suspended rice straw was filtered and washed with hot water until the brown color of lignin disappeared. After drying overnight at $100{ }^{\circ} \mathrm{C}$, a very fine powdered rice straw was obtained and labeled as RS- $\mathrm{H}$.

\subsection{Hydrothermal treatment of RS-H supported iron catalyst}

Preparation of substrate proceeds firstly via hydrothermal treatment of the pretreated rice straw obtained (RS-H). This product known as a hydrochar which has surface densely functionalized polar oxygen groups such as carboxylics, hydroxyls or quinones which make the surface is very active for further chemical process. Typically, a certain amount of RS-H was added to solution containing $2 \mathrm{wt} \%$ ferrocene which dissolved in ethanol. Then, the mixture was sonicated for $90 \mathrm{~min}$ and subsequently changed into a $25 \mathrm{~mL}$ Teflon-lined autoclave tube inside a stainless steel reactor then heated in an electrical muffle at $250{ }^{\circ} \mathrm{C}$ for $120 \mathrm{~min}$. A pale yellow powder of the pretreated rice straw was obtained and denoted as $\mathrm{RS}-\mathrm{H} / \mathrm{Fe}$. After that, it was subjected to CVD process.

\subsection{Preparation of iron and nickel catalysts supported on treated rice straw}

About $2 \mathrm{wt} \%$ of mixture solution containing ferrocene and nickel nitrate $\left(\mathrm{Ni}\left(\mathrm{NO}_{3}\right)_{2} \cdot 6 \mathrm{H}_{2} \mathrm{O}\right)$ were added to pretreated rice straw in a stoppered flask, heated at $100{ }^{\circ} \mathrm{C}$ under stirring for $120 \mathrm{~min}$ then followed by filtration, washing and drying. The produced solid material was then hydrothermally treated in distilled water at $250{ }^{\circ} \mathrm{C}$ for $120 \mathrm{~min}$. Afterward, the produced sample was separated from water and dried at $80{ }^{\circ} \mathrm{C}$ overnight. Finally, the resulting sample (RS-H/Fe-Ni) was subjected to CVD process.

\subsection{Synthesis of carbon nanotubes (CNTs)}

CVD unit comprising two separated chambers, fixed on a desk was employed. A stainless steel tube (diameter $=32 \mathrm{~mm}$ and

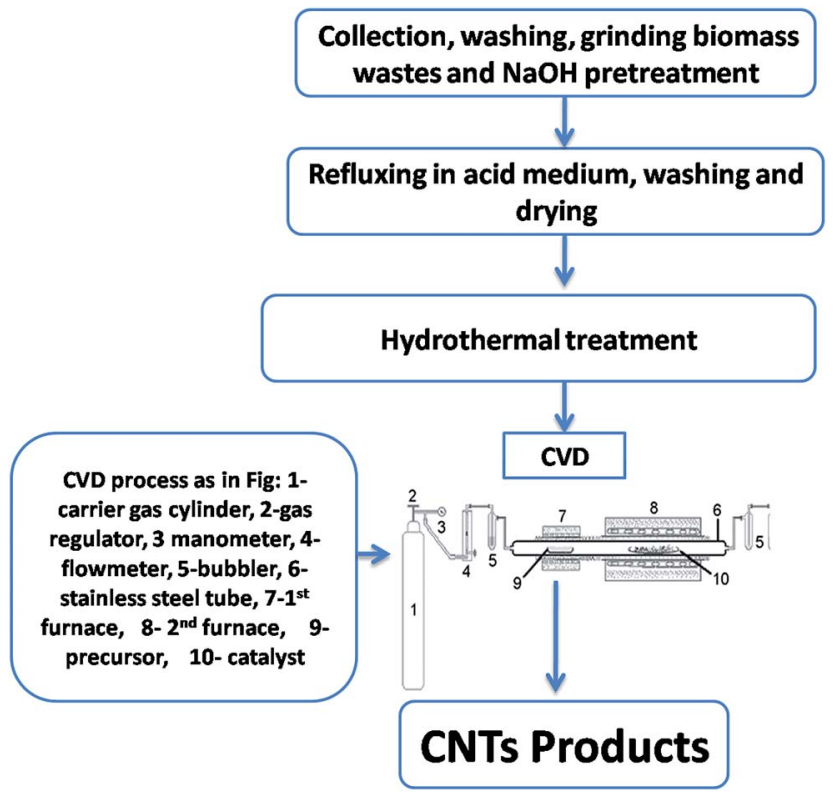

Fig. 1 A flow diagram for synthesis of CNTs from camphor and pretreated rice straw throughout a home-made CVD unit. 
length $=80 \mathrm{~mm}$ ) was placed horizontally throughout two electric furnaces as shown in Fig. 1. Camphor was put inside an alumina boat and transferred into the first furnace (left hand) whereas the resulting substrate with catalyst (RS-H/Fe or RS-H/ $\mathrm{Fe}-\mathrm{Ni}$ ) was inserted in an alumina boat then taken into the other $2^{\text {nd }}$ furnace (right hand). A temperature program was adjusted from room temperature to $800{ }^{\circ} \mathrm{C}$ with a heating rate $\left(10{ }^{\circ} \mathrm{C} \mathrm{min}^{-1}\right)$. When the temperature of $2^{\text {nd }}$ furnace reached $800{ }^{\circ} \mathrm{C}$, it was kept for $120 \mathrm{~min}$, and then the camphor was heated to $250{ }^{\circ} \mathrm{C}$ in order to get the carbon source in the gas phase which then passed throughout the second furnace by the flowing $\mathrm{N}_{2}$ gas at $800{ }^{\circ} \mathrm{C}$ over additional $60 \mathrm{~min}$ to get CNTs deposited on the carbonized RS-H/Fe or RS-H/Fe-Ni. Finally, the two furnaces were switched off and the resulting carbon samples were collected and denoted as CNTs-Fe and CNTs-Fe$\mathrm{Ni}$, respectively.

\subsection{Characterization of the prepared samples}

To draw more detailed description, the prepared samples were characterized with reference to their morphologies before and after formation of CNTs. The surface structure and chemical compositions of the prepared samples were estimated by fieldemission scanning electron microscope (SEM) combined with energy-dispersive spectroscopy and electron backscatter diffraction (FE-SEM, FEI Quanta FEG-250, EDS). High resolution transmission electron microscopy (HR-TEM, JEM-1230, Japan) was used to determine the morphologies of the resulting catalysts and carbon nanotubes (CNTs). Investigation of Raman spectra was carried out at room temperature using Sentera laser Raman spectrometer (Bruker, Germany). The thermal stability of the samples was examined (Shimadzu-60 thermal analyzer, Japan) under passing nitrogen atmosphere at a heating rate of $10{ }^{\circ} \mathrm{C} \mathrm{min}{ }^{-1}$. Moreover, Brunauer-EmmettTeller surface area $\left(S_{\mathrm{BET}}, \mathrm{m}^{2} \mathrm{~g}^{-1}\right)$ was determined using nitrogen adsorption analysis at $-196{ }^{\circ} \mathrm{C}$ (BEL-Sorp, Microtrac Bel Crop, Japan).

\section{Results and discussion}

The chemical composition of elements in an atomic percentage for the pretreated rice straw with $\mathrm{NaOH}$ and $\mathrm{H}_{2} \mathrm{SO}_{4}$ was found to be: $64.7 \%$ C, $24.6 \%$ O, $2.76 \% \mathrm{Na}, 0.05 \% \mathrm{Mg}, 4.02 \% \mathrm{Si}, 0.11 \% \mathrm{Ca}$, $0.37 \% \mathrm{Al}, 0.80 \% \mathrm{~S}$ and $2.59 \% \mathrm{P}$. However, after CVD process, the produced CNTs-Fe-Ni has the following composition: $73.5 \% \mathrm{C}$, $19.8 \% \mathrm{O}, 1.5 \% \mathrm{Fe}, 1.90 \% \mathrm{Ni}, 1.98 \% \mathrm{Na}, 0.81 \% \mathrm{Si}$ and $0.51 \% \mathrm{~S}$. Moreover, the total surface area of CNTs-Fe and CNTs-Fe-Ni was found to be 20 and $35 \mathrm{~m}^{2} \mathrm{~g}^{-1}$, respectively, which is close to the surface area obtained in the former work. ${ }^{10}$

In general, rice straw feedstock mostly contains $32-47 \%$ cellulose, $19-27 \%$ hemicelluloses, 5-24\% lignin and $18.8 \%$ inorganic ashes. ${ }^{26}$ The polysaccharides, cellulose and hemicellulose are intimately associated with lignin in the plant cell wall. Alkali pretreatment is known to separate lignin and silica from lignocellulosic biomass, whereas acid pretreatment is known to separate hemicellulose from inter-fibrillar region completely. ${ }^{26}$ In our previous study, quite differences were obtained in the morphology of rice straw after treating the rice straw with $\mathrm{NaOH} .{ }^{26}$ Chakraborty et al. ${ }^{28}$ affirmed that $\mathrm{NaOH}$ pretreatment can have a substantial affect on the crystallinity, pore structure, accessibility, stiffness, unit cell structure, and orientation of fibrils in cellulosic fibers. Such chemical structure of rice straw can be thus utilized for production of CNTs.

\subsection{Morphological properties of the prepared samples}

Imaging with SEM was used to follow the morphological changes in rice straw before and after pretreatment as seen in Fig. 2(A and B). Before any treatment, the surface of raw rice straw showed smooth, tight and contiguous surface. After hydrothermal treatment, $\mathrm{RS}-\mathrm{H} / \mathrm{Fe}-\mathrm{Ni}$ countered to a rough surface with extensive anomalous porosity and vascular bundles that seem to be severely shrunken compared with untreated rice straw. The concave appearance of the outer surface disappeared as a result of removal of lignin and hemicellulose from the rice straw. Upon direct carbonization of treated rice straw (RS-H/Fe$\mathrm{Ni}$ ) at $800{ }^{\circ} \mathrm{C}$, straight, porous and rolled fibrous of cellulose microstructure was formed as depicted in Fig. 2(C). Thus, the carbonization of pretreated rice straw generated pores as an anchor sites for the catalyst and to serve as growing sites for the catalyst nanoparticles as well. As shown in Fig. 2(D), upon decomposition of camphor at $250{ }^{\circ} \mathrm{C}$, meanwhile carbonization of $\mathrm{RS}-\mathrm{H} / \mathrm{Fe}-\mathrm{Ni}$ was carrying out at $800{ }^{\circ} \mathrm{C}$, numerous bundles of CNTs were produced over the pyrolyzed RS-H/Fe-Ni support and the resulting named as CNTs-Fe-Ni. It is observed that the carbonized RS-H/Fe-Ni support was well covered by a CNTs layer with relatively homogeneous diameter distribution. The as-prepared CNTs bundles seem to anchor directly on the surface of the support. Also, the CNTs can grow on both the surface and inside the pores of this carbonized support.

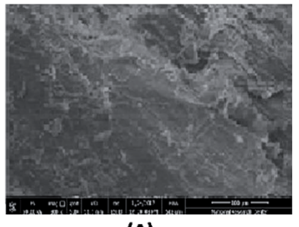

(A)

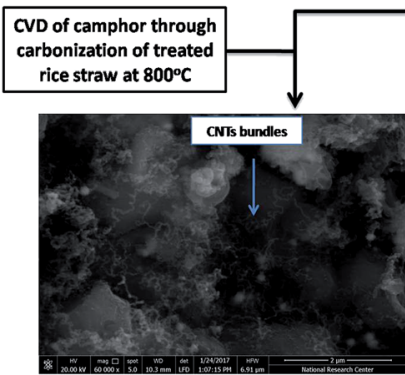

(D)

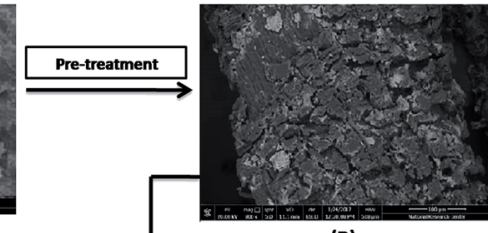

(B)

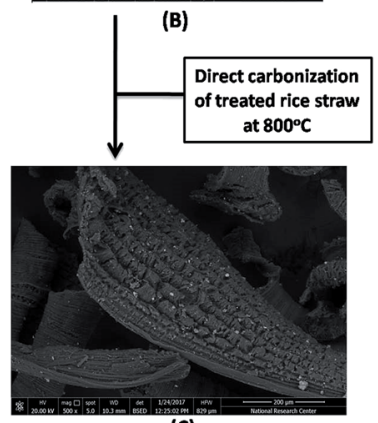

(C)
Fig. 2 SEM images of (A) untreated rice straw, (B) hydrothermally treated rice straw (RS-H/Fe-Ni) at $250{ }^{\circ} \mathrm{C}$ for $120 \mathrm{~min},(\mathrm{C})$ after carbonization of $\mathrm{RS}-\mathrm{H} / \mathrm{Fe}-\mathrm{Ni}$ sample at $800{ }^{\circ} \mathrm{C}$ for $180 \mathrm{~min}$ and (D) CNTs-Fe-Ni produced from CVD of camphor through carbonization of $\mathrm{RS}-\mathrm{H} / \mathrm{Fe}-\mathrm{Ni}$ sample at $800{ }^{\circ} \mathrm{C}$ for $180 \mathrm{~min}$. 


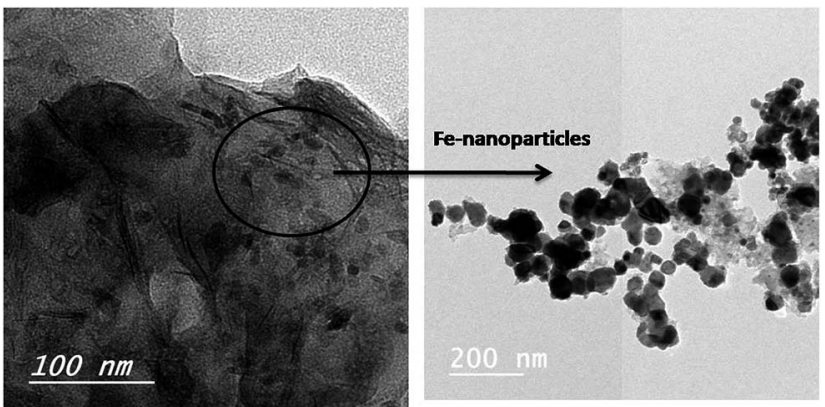

Fig. 3 TEM images of hydrothermally treated rice straw incorporating $2 \mathrm{wt} \%$ ferrocene (RS-H/Fe)

\subsection{Structural properties of the prepared samples}

It has been reported that ferrocene is considered as a potential catalyst for carbon precursor such as camphor to directly prepare CNTs via CVD process..$^{29}$ In this study, the preparation of rice straw incorporated with traces of ferrocene (RS-H/Fe) during hydrothermal reaction at $250{ }^{\circ} \mathrm{C}$ for $120 \mathrm{~min}$ was carried out to act as a catalyst in preparation of CNTs. Fig. 3 represents typical TEM images of the produced sample (RS-H/ $\mathrm{Fe})$ as a catalyst support. It can be seen that irregular graphene sheets incorporated with Fe-nanoparticles catalyst of nanospheres-like were obtained under the effect of hydrothermal process. The black area, appeared on the graphene sheets, was inferred to well-dispersion of ferrocene nanoparticles on their surface. Based on these findings, the studied hydrothermal conditions give rise to produce carbon nanostructures bearing various morphologies.

The strength of the binding force between the $\mathrm{Fe}$ or $\mathrm{Fe}-\mathrm{Ni}$ catalyst and the support should be responsible for the different growth modes. As the binding force is strong, it will gain a tremendous possibility of base/bottom-growth mode with the catalyst particles entrapped in the support and otherwise it will be the tip-growth mechanism. Thus, the interaction of the carbonized rice straw with the metal catalyst is strongly dependent on the intrinsic microstructures and surface properties of the porous support, which in turn affect subsequent carbon growth. ${ }^{30}$

When this sample was exposed to a thermal decomposition at $800{ }^{\circ} \mathrm{C}$ under flowing $\mathrm{N}_{2}$ gas as a carrier for $120 \mathrm{~min}$ and then
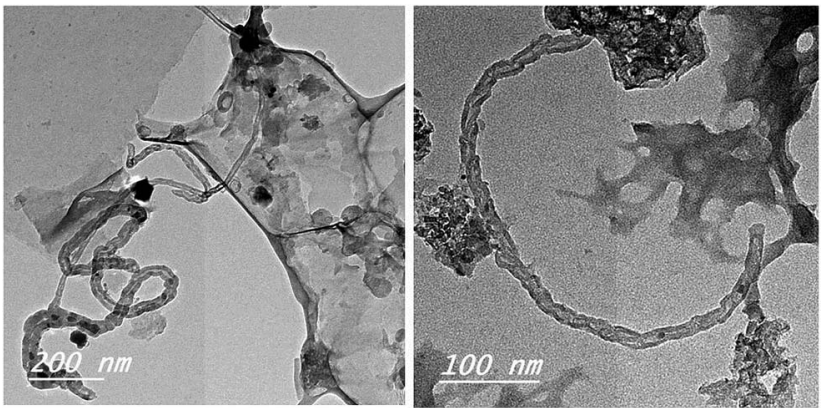

Fig. 4 TEM images of CNTs-Fe synthesized on the carbonize RS-H/ Fe sample through CVD of camphor as gaseous carbon. a gaseous carbon evolved from camphor at $250{ }^{\circ} \mathrm{C}$ was introduced and hold at this temperature for another $60 \mathrm{~min}$, the growth of few coiled CNTs-bundles could be obtained as shown in Fig. 4. The yield of deposited carbon product was $41 \%$. Obviously, the as-synthesized CNTs bundles with external diameter of $\sim 22 \mathrm{~nm}$ was found (Fig. 4) as a result of CVD of camphor on RS-H/Fe catalyst. Comparing Fig. 3 and 4, it can be suggested that the presence of graphene sheets and carbon Fenanoparticles can act as an effective substrate during carbonization of hydrothermally treated rice straw, and thus would accelerate the nucleation of CNTs upon passing gaseous hydrocarbons from vaporized camphor to form a bamboo-like CNTs-bundles denoted as CNTs-Fe (Fig. 4). The tiny amount of CNTs bundles is probably attributed to small amount of ferrocene supported on treated rice straw, where EDX analysis indicated that the presence of low amount of $\mathrm{Fe}$ species $(\sim 0.33 \%)$. Overall, the hydrothermal carbonization at $250{ }^{\circ} \mathrm{C}$ could lead to formation of nanoscale spheres that are derived from the reorganization inside the amorphous structure of lignocellulosic rice straw giving rise to ablation of cell wallmicrofibriles in the carbonized structure as described elsewhere by others. ${ }^{23}$ These walls of the tubes constructed of a hexagonal lattice of carbon atoms and capped by fullerene-like structures.

In a further attempt, the rice straw treated hydrothermally with ferrocene and nickel nitrate (RS-H/Fe-Ni) was subjected to CVD process in the presence of camphor and $\mathrm{N}_{2}$ gas as a carrier, keeping the temperature and time of growth unchanged as mentioned above. The product yield was calculated to be $44 \%$. The morphology acquired by the prepared sample is illustrated in Fig. 5 which shows the formation of twisted individual CNTs bundles with large outer diameter equal to $\sim 66 \mathrm{~nm}$ with respect to the diameters of Fe-Ni bi-catalysts nanoparticles formed in the tip of tubes (as black spots). The produced CNTs labelled as CNTs-Fe-Ni. Comparing the two prepared CNTs indicates that the presence of $\mathrm{Ni}$ oxide nanoparticles with $\mathrm{Fe}$ nanoparticles released from ferrocene would enhance the amount and increase the thickness of the as-synthesized CNTs (Fig. 5). Thus the CNTs obtained from CVD of camphor over RS-H/Fe-Ni have larger outer diameters and somewhat longer length as compared to CNTs-Fe. The results in Fig. 4 and 5 shown that the growth regime of CNTs over the carbonized RS-H/Fe or RS-

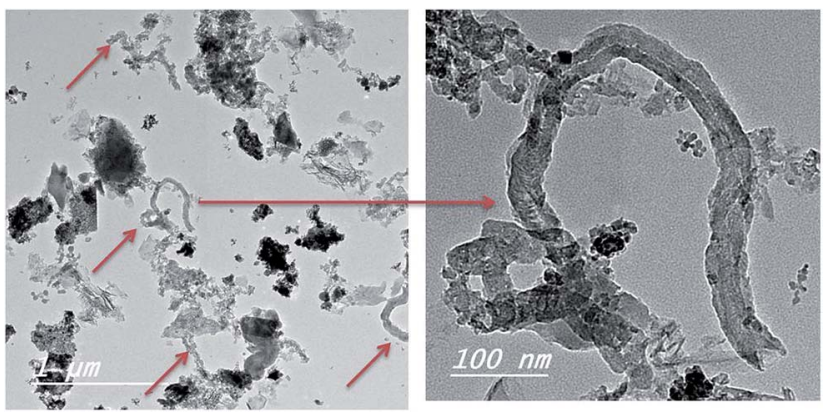

Fig. 5 TEM images of CNTs-Fe-Ni synthesized (as marked by arrows) on the carbonized RS-H/Fe-Ni sample during CVD process of camphor as gaseous carbon. 


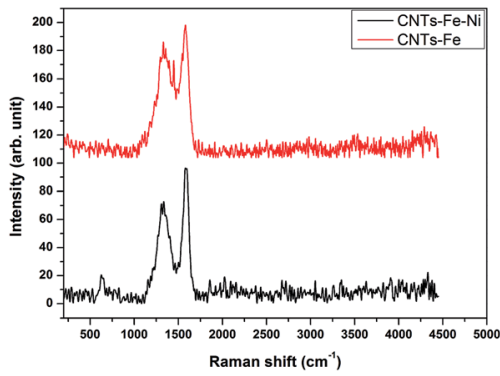

Fig. 6 Raman spectra of the prepared CNTs from CVD of camphor during carbonization of RS-H/Fe and RS-H/Fe-Ni samples at $800^{\circ} \mathrm{C}$.

$\mathrm{H} / \mathrm{Fe}-\mathrm{Ni}$ support follows a bottom-growth, implying a strong interaction between the carbon matrix in the carbonized rice straw with $\mathrm{Fe}$ and $\mathrm{Fe}-\mathrm{Ni} .^{30}$

The Raman technique has been proved to be a useful tool for determining the microstructure of crystalline ordering in carbonaceous materials such as CNTs. ${ }^{31,32}$ The Raman spectra of produced CNTs-Fe and CNTs-Fe-Ni are shown in Fig. 6 . There are two prevalent graphite bands in the Raman spectra of CNTs: the band at $1580 \mathrm{~cm}^{-1}$ is assigned to the in-plane vibration of the $\mathrm{C}-\mathrm{C}$ bond ( $\mathrm{G}$ band) and considered a typical of graphite-like materials and the band at nearly $1356 \mathrm{~cm}^{-1}$ for CNTs-Fe is shifted to $1335 \mathrm{~cm}^{-1}$ for CNTs-Fe-Ni which ascribed to D-band as a result of the presence of disorder in carbon materials. On another speaking, the G-peak is attributed to the $\mathrm{E}_{2 \mathrm{~g}}$ mode of highly oriented pyrolytic graphite structure, while the D-peak reflects structural imperfections in the graphite sheets, such as impurities/defects in the materials. ${ }^{31}$ The graphitization of graphene-family nanomaterials can be obtained by comparing the relative integrated intensity of D-peak to G-peak $\left(I_{\mathrm{D}} / I_{\mathrm{G}}\right)$. It was found that this intensity ratio of two peaks $\left(I_{\mathrm{D}} / I_{\mathrm{G}}\right)$ was 0.753 in CNTs-Fe-Ni and 0.942 in CNTs-Fe, i.e., the CNTs produced over the carbonized $\mathrm{RS}-\mathrm{H} / \mathrm{Fe}-\mathrm{Ni}$ are well-graphitized as compared to that grown over RS-H/Fe. Thus the combination of $\mathrm{Ni}$ with ferrocene can enhance both the graphitization degree and quantity of CNTs. Also, this observation is agreed with HRTEM images also. In conclusion, the quality of the as-prepared
CNTs was applicable enough to the study in many industrial applications, for example, the application in construction concrete without purification due to the compatibility between the materials.

Results of thermogravimetric (TGA) carried out under nitrogen atmosphere from room temperature to $900{ }^{\circ} \mathrm{C}$ are illustrated in Fig. 7. For RS-H/Fe-Ni, corresponding to hydrothermally treated rice straw at $250{ }^{\circ} \mathrm{C}$, TGA profile shows three thermal degradation regions; $25-250{ }^{\circ} \mathrm{C}, 250-350^{\circ} \mathrm{C}$ and $350-$ $800^{\circ} \mathrm{C}$. At these regions the weight losses were found to be 12.5 , 48.7 and $19.8 \%$, respectively. Thus the main degradation occurred at the second region due to the degradation of cellulose-related component to form amorphous carbon, while decomposition of lignin happened over $450{ }^{\circ} \mathrm{C}$ in the third region, leaving $19 \%$ residual which is possibly related to the presence of graphitic carbon with remaining inorganic components. ${ }^{33}$ The high content of residual weight indicates the presence of catalyst species, considering that the prepared samples were purified with a mixture of acid solutions $\left(\mathrm{HNO}_{3}\right.$ and $\mathrm{H}_{2} \mathrm{SO}_{4}$ ). On the other hand, TGA profile of CNTs-Fe-Ni exhibits different interfering regions as compared to RS-H/Fe$\mathrm{Ni}$. The weight loss reached to $11.2 \%$ during thermal degradation between room temperature and $900{ }^{\circ} \mathrm{C}$. Thus the asprepared CNTs-Fe-Ni has a high thermal stability due to its higher graphitic carbon content $(\sim 88.8 \%)$. During increment in thermal degradation from 200 to $750{ }^{\circ} \mathrm{C}$, there is a continuous loss of weight that may be attributed to degradation of organic matters coming from the pyrolysis of saw dust which is counted to be $\sim 5.9 \%$ with respect to the original weight. This result is in agreement with a recent work in the literature..$^{34}$

\section{Conclusions}

Here, for the first time, the CNTs was synthesized through carbonization of rice straw treated hydrothermally in presence of low doses from catalyst sources, e.g., ferrocene or ferrocene with nickel nitrate salt (RS-H/Fe or $\mathrm{RS}-\mathrm{H} / \mathrm{Fe}-\mathrm{Ni}$ ) via chemical vapor deposition of camphor. Few amounts, small outer diameters and coiled bundles of CNTs were produced over carbonized rice straw with ferrocene (RS-H/Fe) through bottom
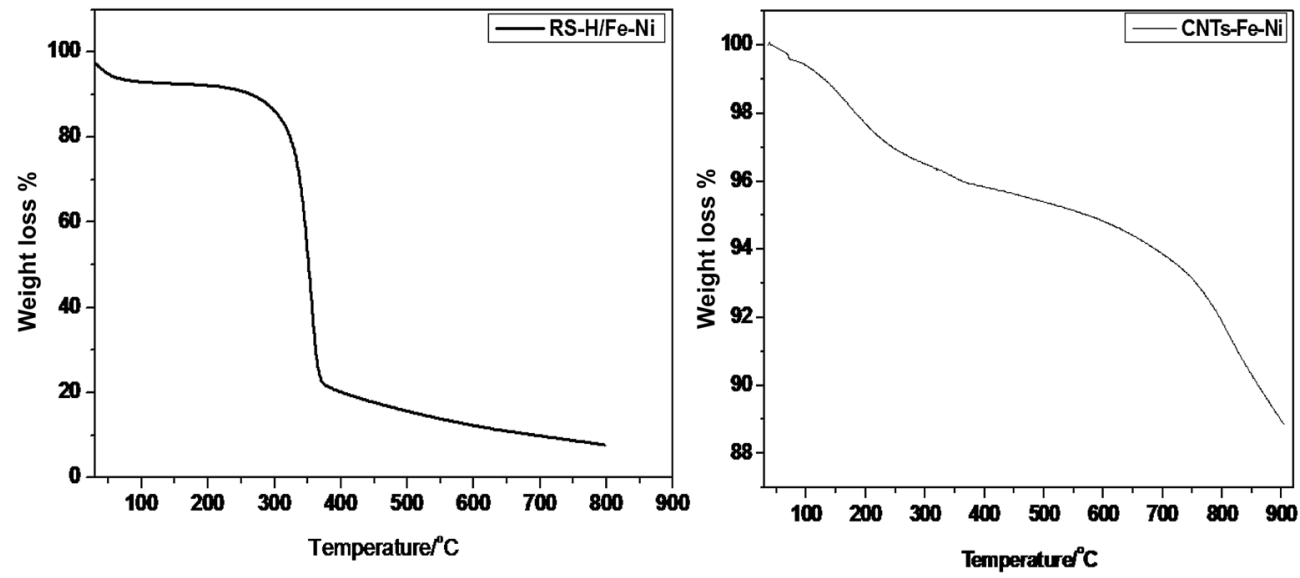

Fig. 7 TGA profiles of the prepared samples before and after synthesis CNTs. 


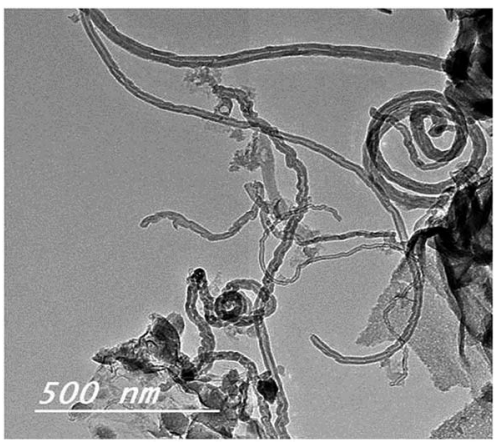

Fig. 8 TEM image of the prepared CNTs from hydrothermal carbonization of $\mathrm{RS}-\mathrm{H} / \mathrm{Fe}-\mathrm{Ni}$.

growth mechanism. Whereas considerable amounts of straight and large outer diameter of CNTs-bundles were formed over carbonized RS-H/Fe-Ni via bottom growth mechanism also as detected in TEM images. Furthermore, Raman spectra confirmed the formation of CNTs on the carbonized rice straw through the prescribed technique in this study. Accordingly, the structure and diameter of the produced CNTs were found to be controlled by the morphological properties of the prepared catalysts on the carbonized rice straw. It was found that the prepared $\mathrm{RS}-\mathrm{H} / \mathrm{Fe}-\mathrm{Ni}$ was more efficient as compared to RS-H/ $\mathrm{Fe}$ in the production of CNTs. Overall, the feasibility of carbonized rice straw treated with $\mathrm{Fe}-\mathrm{Ni}$ catalyst as an efficient substrate for preparation of CNTs through chemical vapor deposition of camphor under flowing $\mathrm{N}_{2}$ gas was successfully attained. However, still there are more attempts in our laboratory to optimize the synthesis procedure and to prepare good quality and high quantity of CNTs. In an ongoing study, when $\mathrm{RS}-\mathrm{H} / \mathrm{Fe}-\mathrm{Ni}$ exposed to a thermal treatment in a closed-vertical tubular furnace at $800{ }^{\circ} \mathrm{C}$ for $60 \mathrm{~min}$, without flow of any inert gases, good quality of CNTs with large amount is obtained as shown in Fig. 8.

\section{Acknowledgements}

The author gratefully acknowledges the financial supports provided by the National Research Centre (NRC) under the Project No. 11090201.

\section{References}

1 S. Iijima, Helical microtubules of graphitic carbon, Nature, 1991, 354, 56-58.

2 M. F. L. De Volder, S. H. Tawfick, R. H. Baughman and A. John Hart, Carbon Nanotubes: Present and Future Commercial Applications, Science, 2013, 339, 535-539.

3 Carbon Filaments and Nanotubes: Common Origins, Differing, Applications?, ed. L. P. Biró, C. A. Bernardo, G. G. Tibbetts and P. H. Larnbin, Kluwer Academic, Dordrecht, Netherlands, 2001.

4 R. H. Baughman, A. A. Zakhidov and W. A. de Heer, Carbon nanotubes-the route toward applications, Science, 2002, 297(787).
5 A. Jha, U. K. Ghorai, D. Banerjee, S. Mukherjee and K. K. Chattopadhyay, Surface modification of amorphous carbon nanotubes with copper phthalocyanine leading to enhanced field emission, RSC Adv., 2013, 3, 1227-1234.

6 H. Dai, Carbon Nanotubes: Synthesis, Integration, and Properties, Acc. Chem. Res., 2002, 35, 1035-1044.

7 Carbon Materials for Catalysis, ed. P. Serp and J. L. Figueiredo, John Wiley \& Sons Inc, New Jersey, 2009.

8 D. Yu, E. Nagelli, F. Du and L. Dai, Metal-free carbon nanomaterials become more active than metal catalysts and last longer, J. Phys. Chem. Lett., 2010, 1, 2165-2173.

9 H. Chu, L. Wei, R. Cui, J. Wang and Y. Li, Carbon nanotubes combined with inorganic nanomaterials: preparations and applications, Coord. Chem. Rev., 2010, 254, 1117-1134.

10 A. Peigney, C. Laurent, E. Flahau, R. R. Bacsa and A. Rousset, Specific surface area of carbon nanotubes and bundles of carbon nanotubes, Carbon, 2001, 39, 507-514.

11 C. Journet, W. K. Maser, P. Bernier, A. Loiseau, M. L. dela Chapelle, S. Lefrant, P. Deniard, R. Lee and J. E. Fischer, Large-scale production of single-walled carbon nanotubes by the electric arc technique, Nature, 1997, 388(6644), 756.

12 T. Guo, P. Nikolaev, A. Thess, D. T. Colbert and R. E. Smalley, Catalytic growth of single-walled nanotubes by laser vaporization, Chem. Phys. Lett., 1995, 243(1-2), 49.

13 H. Dai, A. G. Rinzler, P. Nikolaev, A. Thess, D. T. Colbert and R. E. Smalley, Single-wall nanotubes produced by metalcatalyzed disproportionation of carbon monoxide, Chem. Phys. Lett., 1996, 260(3-4), 471.

$14 \mathrm{M}$. Kumar and Y. Ando, Camphor-a botanical precursor producing garden of carbon nanotubes, Diamond Relat. Mater., 2003, 12, 998-1002.

15 R. J. Andrews, C. F. Smith and A. J. Alexander, Mechanism of carbon nanotubes growth from camphor and camphor analogs by chemical vapor deposition, Carbon, 2006, 44, 341-347.

16 A. K. Chatterjee, M. Sharon, R. Banerjee and M. NeumannSpallart, CVD synthesis of carbon nanotubes using a finely dispersed cobalt catalyst and their use in double layer electrochemical capacitors, Electrochim. Acta, 2003, 48, 3439.

17 X. Liu, Y. Yang, H. Liu, W. Ji, C. Zhang and B. Xu, Carbon nanotubes from catalytic pyrolysis of deoiled asphalt, Mater. Lett., 2007, 61, 3916-3919.

18 P. Ghosh, R. A. Afre, T. Soga and T. Jimbo, A simple method of producing single-walled carbon nanotubes from a natural precursor: eucalyptus oil, Mater. Lett., 2007, 61, 3768-3770.

19 S. Paul and S. K. Samdarshi, A green precursor for carbon nanotubes synthesis, New Carbon Mater., 2011, 26, 85-88.

20 R. Kumar, R. S. Tiwari and O. N. Srivastava, Scalable synthesis of aligned carbon nanotubes bundles using green natural precursor: neem oil, Nanoscale Res. Lett., 2011, 6, 92.

21 A. B. Suriani, A. A. Azira, S. F. Nik, R. Md Nor and M. Rusop, Synthesis of vertically aligned carbon nanotubes using natural palm oil as carbon precursor, Mater. Lett., 2009, 63, 2704-2706.

22 A. B. Suriani, R. Md Nor and M. Rusop, Vertically aligned carbon nanotubes synthesized from waste cooking palm oil, J. Ceram. Soc. Jpn., 2011, 118, 963-968. 
23 B. Goodell, X. Xie, Y. Qian, G. Daniel, M. Peterson and J. Jellison, Carbon nanotubes produced from natural cellulosic materials, J. Nanosci. Nanotechnol., 2008, 8(5), 2472-2474.

24 J. Zhu, J. Jia, F. L. Kwong, D. H. Ng and S. C. Tjong, Synthesis of multiwalled carbon nanotubes from bamboo charcoal and the roles of minerals on their growth, Biomass Bioenergy, 2012, 36, 12-19.

25 Z. Wang, H. Ogata, S. Morimoto, J. Ortiz-Medina, M. Fujishige, K. Takeuchi, H. Muramatsu, T. Hayashi, M. Terrones, Y. Hashimoto and M. Endo, Nanocarbons from rice husk by microwave plasma irradiation: from graphene and carbon nanotubes to graphenated carbon nanotubes hybrids, Carbon, 2015, 94, 479-484.

26 E. B. Belal, Bioethanol production from rice straw residues, Braz. J. Microbiol., 2013, 44, 225-234.

27 N. A. Fathy, O. I. El-Shafey and L. B. Khalil, Effectiveness of alkali-acid treatment in enhancement the adsorption capacity for Rice straw: the removal of methylene blue dye., ISRN Phys. Chem., 2013, 2013, 1-15.
28 S. Chakraborty, S. Chowdhury and P. Saha, Adsorption of crystal violet from aqueous solution onto $\mathrm{NaOH}$-modified rice husk, Carbohydr. Polym., 2011, 86, 1533-1541.

29 M. Kumar and Y. Ando, A simple method of producing aligned carbon nanotubes from an unconventional precursor - Camphor, Chem. Phys. Lett., 2003, 374, 521-526.

30 F. Zhou, Q. Liu, W. Zhang, J. Gu, S. Zhu and D. Zhang, Fabrication of 3D carbon nanotube/porous carbon hybrid materials, J. Mater. Sci., 2014, 49, 548-557.

31 M. S. Dresselhaus, G. Dresselhaus, R. Saito and A. Jorio, Raman spectroscopy of carbon nanotubes, Phys. Rep., 2005, 409, 47-99.

32 H. Essawy, N. Fathy, M. Tawfik, S. El-Sabbagh, N. Ismail and H. Youssef, Fabrication of Single-Walled Carbon Nanotubes from Vulcanized Scrap Rubber via Thermal Chemical Vapor Deposition, RCS Adv., 2017, 7, 12938-12944.

33 P. Lu and Y.-L. Hsieh, Highly pure amorphous silica nanodisks from rice straw, Powder Technol., 2012, 225, 149-155.

34 M. G. S. Bernd, S. R. Braganc, N. Heck and L. C. P. da Silva Filho, Synthesis of carbon nanostructures by the pyrolysis of wood sawdust in a tubular reactor, J. Mater. Res. Technol., 2017, DOI: 10.1016/j.jmrt.2016.11.003. 